\title{
STUDY ON CAUSE-EFFECT RELATIONS AND OPTIMIZATION OF EXEMESTANE-LOADED NANOSTRUCTURED LIPID CARRIERS
}

\author{
LE QUOC THANG, NGUYEN DUC HANH*, DO QUANG DUONG
}

Faculty of Pharmacy, University of Medicine and Pharmacy at Ho Chi Minh City, Vietnam

Email: duchanh@uphcm.edu.vn

Received: 29 Jan 2017 Revised and Accepted: 09 Mar 2017

\section{ABSTRACT}

Objective: Exemestane is an anti-breast cancer drug, possesses low water solubility and low permeability. This work aimed at the cause-effect relations and optimization of exemestane-loaded nanostructured lipid carriers (EXE-NLCs) for oral delivery.

Methods: Excipient screening was based on exemestane solubilities and the emulsification efficiency of surfactants. A D-optimal design based on three independent variables was applied to evaluate the cause-effect relations and optimise EXE-NLCs formulation. The particle size (PS), polydispersity index (PDI), entrapment efficiency (EE) and drug loading (DL) were investigated with respect to three independent variables including liquid lipid to total lipid ratio $\left(\mathrm{X}_{1}\right)$, surfactant concentration $\left(\mathrm{X}_{2}\right)$, total lipid concentration $\left(\mathrm{X}_{3}\right)$.

Results: EXE-NLCs were prepared by a hot sonication method employing Labrafac CC and Compritol 888ATO as liquid and solid lipids, respectively, and Cremophor RH40 as a surfactant and Lutrol E-400 as a co-surfactant. All investigated factors: liquid lipid to total lipid ratio, surfactant concentration and total lipid concentration showed significant influences on physicochemical characteristics of EXE-NLCs. The optimal EXE-NLC formulation was composed of liquid lipid to total lipid ratio $\left(\mathrm{X}_{1}\right)$ of $24 \%(\mathrm{w} / \mathrm{w})$, surfactant concentration $\left(\mathrm{X}_{2}\right)$ of $4 \%$ (w/v) and total lipid concentration $\left(\mathrm{X}_{3}\right)$ of $4 \%$ (w/v). The PS, PDI, EE and DL of the optimized EXE-NLCs were found to be $41.787 \mathrm{~nm} ; 0.11 ; 97.605 \%$ and $1.935 \%$, respectively. The optimized formulation was experimentally examined which demonstrated a good agreement between experimental and predicted values.

Conclusion: The cause-effect relations and optimization of EXE-NLCs were investigated and reported for the first time. EXE-NLCs formulation was successfully optimized using D-optimal design and merits further study.

Keywords: Exemestane, Optimization, NLC, BCPharSoft OPT software

(C) 2017 The Authors. Published by Innovare Academic Sciences Pvt Ltd. This is an open access article under the CC BY license (http://creativecommons.org/licenses/by/4.0/) DOI: http://dx.doi.org/10.22159/ijpps.2017v9i5.17354

\section{INTRODUCTION}

Exemestane (fig. 1) is an anti-breast cancer drug inhibits irreversibly the activity of aromatase, the key enzyme that converts androgens to oestrogens [1]. Exemestane has been approved by the food and drug administration (FDA) for the treatment of breast cancer in postmenopausal women [2].

However, exemestane is a BCS (bio pharmaceutics classification system) class IV drug with a poor water solubility $(0.08 \mathrm{mg} / \mathrm{ml})$ and low permeability. Therefore, the bioavailability of exemestane was reported to be low in various animal models at a single dose of 25 mg [3].<smiles>C=C1C[C@H]2[C@@H]3CCC(=O)[C@@]3(C)CC[C@H]2[C@@]2(C)C=CC(=O)C=C12</smiles>

Fig. 1: Structure of exemestane [3]

Different formulation strategies have been employed to overcome the aforementioned biopharmaceutical challenges associated with exemestane such as pro-liposomes [4], polycaprolactone nanoparticles [5], poly (D, L-lactide-co-glycolide)/montmorillonite nanoparticles [6], polymeric nanoparticles [7] and self-emulsifying drug delivery system [3]. However, there are missing studies for lipid nanoparticles.

Lipid nanoparticles, such as solid lipid nanoparticles (SLNs) and the nanostructured lipid carriers (NLCs) are the promising carriers for a lipophilic molecule due to their potential to increase the solubility of the lipophilic drug [8,9]. NLCs are second-generation of lipid nanoparticles developed using a blend of solid and liquid lipid. NLCs offer many advantages such as good biocompatibility, controlled drug release and the possibility of production on the large industrial scale $[10,11]$. Moreover, a high drug loading efficiency can be achieved with the use of NLC $[12,13]$.

The aim of this study was to investigate the cause-effect relations between independent and dependent variables and develop the formulation of EXE-NLCs using D-optimal design and BCPharSoft OPT intelligent software.

\section{MATERIALS AND METHODS}

\section{Materials}

Exemestane (98.90\% purity) was purchased from Qilu Pharmaceutical Co., Ltd. (China). Compritol 888ATO (glyceryl dibehenate), Geleol mono and diglycerides NF (Glycerol monostearate 40-55 type 1, GMS), Capryol 90 (propylene glycol monocaprylate), Maisine 35-1 (glyceryl monooleate), Labrasol (caprylocaproyl polyoxylglycerides), Labrafac CC (caprylic/capric triglycerides), and Labrafac lipophile WL 1349 (caprylic/capric triglycerides) were received from Gattefosse (Saint-Priest Cedex, France) via Sapharchem Co., Ltd (Vietnam). Cremophor RH40 (Polyoxyl 40 Hydrogenated Castor Oil), Cremophor EL (polyoxyl 35 castor oil) and Lutrol E-400 (polyethylene glycol) were the gifts from BASF (Germany). Miglyoil 812 (caprylic/capric triglycerides) was received from Sasol GmBH (Germany). Gac oil was a gift from 
Vnpofood (Vietnam). All other chemicals were of analytical grade.

\section{Analytical method of exemestane}

Exemestane was analyzed by an Azura HPLC system (Knauer, Germany). The separation was performed on a Syncronis C18 column ( $250 \times 4.6 \mathrm{~mm} ; 5 \mu \mathrm{m})$ (Thermo Scientific, USA). The mobile phase was acetonitrile: water $(75: 25, \mathrm{v} / \mathrm{v})$ with a flow rate of $1 \mathrm{ml} / \mathrm{min}$. Detection was performed at a wavelength of $247 \mathrm{~nm}$ at $30^{\circ} \mathrm{C}$. The sample injection volume was $20 \mu \mathrm{l}$.

\section{Excipient screening}

\section{Solubility studies}

The saturation solubility of exemestane in various liquid lipids (Miglyol 812, Labrafac CC, Labrafac lipophile WL 1349, Gac oil, Capryol 90 and Maisine 35-1), surfactants (Labrasol, Cremophor RH40, Cremophor EL), co-surfactant (Lutrol E-400) were determined. Excess amounts of exemestane were added into individual tubes containing $1 \mathrm{ml}$ of different liquid lipids, surfactants, co-surfactants and mixed using a vortex mixer (VortexGenie 2, Scientific Industries, Inc., New York, USA).

The capped tubes were then continuously shaking to reach equilibrium for $72 \mathrm{~h}$ at $25{ }^{\circ} \mathrm{C}$ on a Labquake shaker (Barnstead Thermolyne, USA). The equilibrated samples were centrifuged at $10,000 \mathrm{rpm}$ for $10 \mathrm{~min}$. The supernatant was separated and filtered through a $0.22 \mu \mathrm{m}$ membrane and diluted in ethanol. Exemestane concentrations were analyzed using a validated HPLC method. Each determination was carried out in triplicate and the results were reported as \pm SD [14].

\section{Miscibility of solid and liquid lipids}

The three liquid lipids in which exemestane exhibited maximum solubilities and two solid lipids (Geleol mono and diglycerides NF, Compritol 888ATO) were subjected to a miscibility test. The melted mixtures of solid and liquid lipids in a ratio of $3: 1(\mathrm{w} / \mathrm{w})$ were checked by visual observation to select the binary lipid phase. Each mixture was observed for clarity, uniformity, turbidity, phase separation and left to cool down to room temperature. The mixture which exhibited good miscibility was selected as the binary lipid phase for the NLC design.

\section{Surfactant screening}

The binary lipid phase was melted at $85^{\circ} \mathrm{C}$. The homogenous aqueous phase included surfactant, co-surfactant and double distilled water was heated to the same temperature and added drop wise into lipid phase to a liquid lipid/solid lipid/surfactant/co-surfactant ratio of 3:9:9:1 (w/w/w/w). The mixture was then dispersed under magnetic stirring at $600 \mathrm{rpm}$ for $15 \mathrm{~min}$ and diluted by cold water $\left(4^{\circ} \mathrm{C}\right)$ to a volume of $50 \mathrm{ml}$ and continued stirring for $5 \mathrm{~min}$. The best surfactant was selected based on its emulsifying potential.

\section{Preparation of EXE-NLCs}

EXE-NLCs were prepared by a hot sonication technique [15]. $40 \mathrm{mg}$ exemestane was dissolved in a melted mixture of solid and liquid lipid at $85{ }^{\circ} \mathrm{C}$ as a lipid phase. The aqueous phase containing surfactant, co-surfactant and double distilled water was heated to the same temperature and added drop by drop into the lipid phase under continuous magnetic stirring at $600 \mathrm{rpm}$ for $15 \mathrm{~min}$ followed by sonication (Sonorex, RK-1028, Bandelin, Japan) at $85^{\circ} \mathrm{C}$ to obtain microemulsion. The hot microemulsion was diluted by cold water $(4$ ${ }^{\circ} \mathrm{C}$ ) to a volume of $50 \mathrm{ml}$ and continued stirring for $1 \mathrm{~h}$ to cool down to room temperature. The quantities of excipients were varied at different levels (table 1).

\section{Experimental design and data analysis}

A D-optimal design with a total of 10 experimental runs was generated by Design Expert software (version 6.0.6, Stat-Ease Inc., Minneapolis, USA) to study the effects of independent variables on dependent variables. Liquid lipid to total lipid ratio $\left(\mathrm{X}_{1}\right)$, surfactant concentration $\left(\mathrm{X}_{2}\right)$ and total lipid concentration $\left(\mathrm{X}_{3}\right)$ were selected as three independent variables whereas particle size $\left(\mathrm{Y}_{1}\right)$, polydispersity index $\left(\mathrm{Y}_{2}\right)$, entrapment efficiency $\left(\mathrm{Y}_{3}\right)$ and drug loading $\left(\mathrm{Y}_{4}\right)$ were chosen as four dependent variables.

Liquid lipid to total lipid ratio $\left(\mathrm{X}_{1}\right)$ and surfactant concentration $\left(\mathrm{X}_{2}\right)$ were studied at two levels and total lipid concentration $\left(\mathrm{X}_{3}\right)$ was studied at three levels. For each independent variable, the experimental range was selected based on the results of initial trials. The details of the design are listed in table 1 . All formulations in these experiments were conducted in triplicate. Data were exhibited as mean \pm standard deviation [16].

The optimized formulation was performed in triplicate for validation. The observed response data of the optimized formulation were compared with their predicted data created by BCPharSoft OPT software using SPSS version 20.0 (SPSS, Inc., Chicago, IL, USA).

\section{Particle size and polydispersity index}

Particle size and a polydispersity index of NLCs were measured at $25{ }^{\circ} \mathrm{C}$ by photon correlation spectroscopy using a Zetasizer Nano ZS (Malvern Instruments Ltd., Worcestershire, UK) at a fixed angle of $173^{\circ}$ in $10 \mathrm{~mm}$ diameter cells [17]. Samples were diluted tenfold with double distilled water to produce a suitable scattering intensity before analysis. All measurements were carried out in triplicate.

\section{Determination of entrapment efficiency and drug loading}

The entrapment efficiency (EE) and drug loading (DL) was indirectly determined by measuring the concentration of free exemestane in the lower chamber of centrifugal filter tubes with a molecular weight cut-off of 3500 Da (Amicon Ultra $0.5 \mathrm{ml}$, Merck Millipore, Germany). About $400 \mu \mathrm{l}$ of NLCs suspension was placed in the upper chamber of centrifugation tube, followed by centrifugation at $30000 \mathrm{x} \mathrm{g}$ (Hermle, Z36HK, Germany) at $20{ }^{\circ} \mathrm{C}$ for $15 \mathrm{~min}$ [18]. The free exemestane in the filtrates was analyzed by an HPLC analytical method described aforementioned. The studies were performed in triplicate. Entrapment efficiency and drug loading were calculated by the following equations:

Table 1: Variables in experimental design

\begin{tabular}{|c|c|c|c|}
\hline & \multicolumn{3}{|c|}{ Levels } \\
\hline & Low & Medium & High \\
\hline \multicolumn{4}{|l|}{ Independent variables } \\
\hline $\mathrm{X}_{1}$ : Liquid lipid to total lipid ratio $(\%, w / w)$ & 10 & 30 & \\
\hline $\mathrm{X}_{2}$ : Surfactant concentration $(\%, \mathrm{w} / \mathrm{v})$ & 2 & 4 & \\
\hline $\mathrm{X}_{3}$ : Total lipid concentration $(\%, \mathrm{w} / \mathrm{v})$ & 4 & 6 & 8 \\
\hline Dependent variables & \multicolumn{3}{|c|}{ Constraints } \\
\hline $\mathrm{Y}_{1}:$ Particle size $(\mathrm{nm})$ & \multicolumn{3}{|c|}{ Minimum } \\
\hline $\mathrm{Y}_{2}$ : Polydispersity index & \multicolumn{3}{|c|}{ Minimum } \\
\hline $\mathrm{Y}_{3}$ : Entrapment efficiency (\%) & \multicolumn{3}{|c|}{ Maximum } \\
\hline $\mathrm{Y}_{4}$ : Drug loading (\%) & \multicolumn{3}{|c|}{ Maximum } \\
\hline
\end{tabular}

The results of experimental design were analyzed using BCPharSoft OPT software (Vietnam). The best fitting model was chosen. In order to achieve a better understanding of the cause-effect relations between the independent and dependent variables, the 3D diagrams of the fitted models were depicted. D-optimal design employed for the study is shown in table 2. 


$$
\begin{aligned}
& \% E E=\frac{\text { total amount of drug - amount of free drug }}{\text { total amonnt af drug }} \times 100 \% \\
& \% D L-\frac{\text { total amount of drug - amount of free drug }}{\text { amount of total lipid }} \times 100 \%
\end{aligned}
$$

\section{RESULTS AND DISCUSSION}

\section{Analytical method of exemestane}

A well-resolved HPLC chromatogram of exemestane was obtained following the use of an acetonitrile: water mobile phase in a ratio of $(75: 25, \mathrm{v} / \mathrm{v})$. The total run time was approximately $7 \mathrm{~min}$ and the retention time of exemestane was at $5.7 \mathrm{~min}$ (fig. 2). In a concentration range of $8-200 \mu \mathrm{g} / \mathrm{ml}$, a good correlation coefficient was observed between peak areas and concentrations of exemestane standard solutions $\left(\mathrm{r}^{2}=0.9995\right)$. Recovery values ranged from $93.06 \%$ to 99.39

$\%$. The coefficient of variation of the within-day precision, expressed as relative standard deviation, was found to be $1.88 \%$. These results indicated that the method was reliable and reproducible.

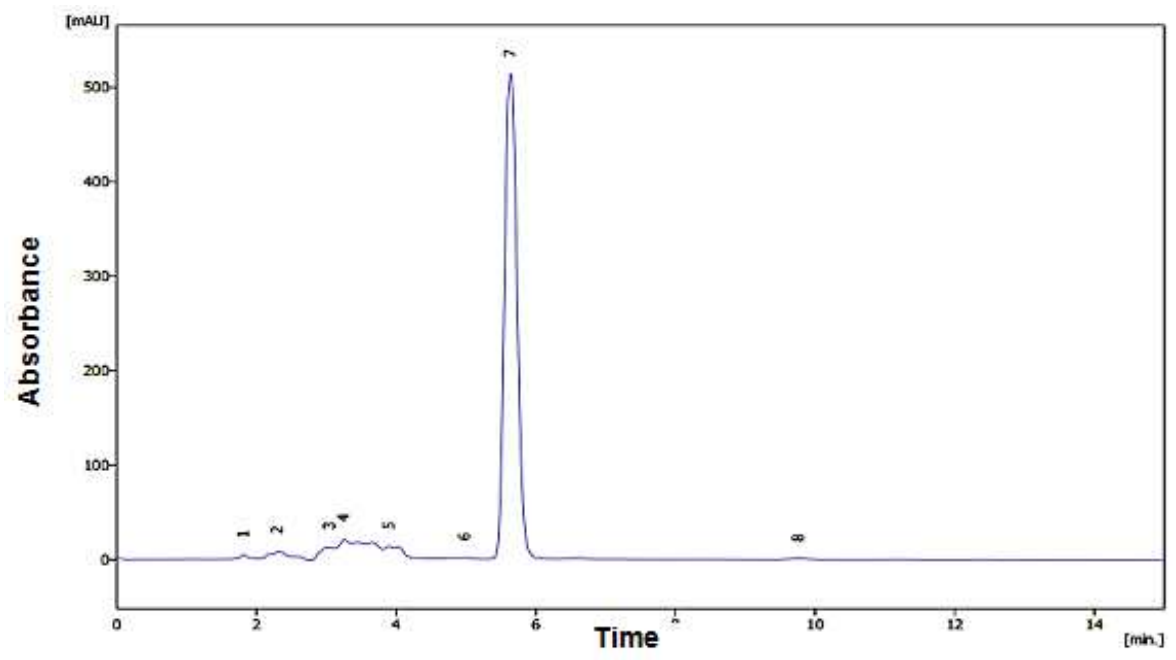

Fig. 2: HPLC chromatograms of exemestane $\left(R_{t}=5.7 \mathrm{~min}\right)$

\section{Excipient screening}

For the selection of liquid lipids, the solubility of exemestane is one of the most important factors. According to the results of solubility studies in liquid lipids (fig. 3), Capryol 90 exhibited the highest solubility of $78.36 \pm 1.03 \mathrm{mg} / \mathrm{ml}$. Maisine $35-1$ and Labrafac CC showed the lower solubilities of $43.32 \pm 0.55 \mathrm{mg} / \mathrm{ml}$ and $24.29 \pm 0.46$ $\mathrm{mg} / \mathrm{ml}$, respectively.

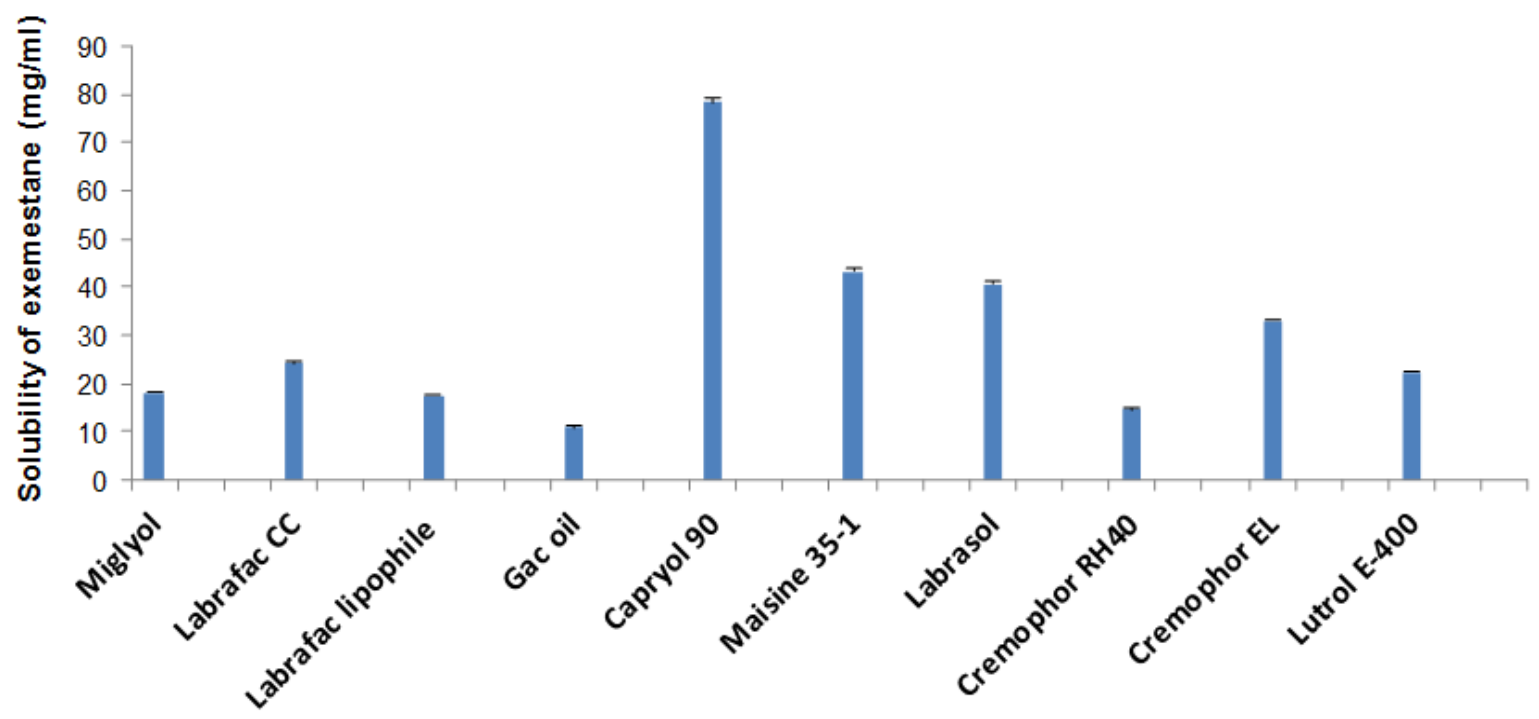

Fig. 3: Solubility of exemestane in liquid excipients at $25^{\circ} \mathrm{C}$. The values represented $\operatorname{mean} \pm S D(n=3)$

The miscibility tests were carried out to avoid the formation of liquid lipid droplets which could lead to the co-existence of EXE-
NLCs and o/w microemulsion. Three liquid lipids with the higher solubilizing capacity (Capryol 90, Maisine 35-1, Labrafac CC) and 
two solid liquids (Geleol, Compritol 888AT0) were subjected to miscibility studies. The mixture of Labrafac CC and Compritol 888ATO showed a very good miscibility. Therefore, Labracfac CC and Compritol 888ATO were selected as liquid and solid lipids for NLC formulation.

Surfactant reduces the interfacial tension between the lipid phase and the aqueous phase, therefore, it was important to choose appropriate surfactant to obtain the desired size and the long-term physical stability of NLCs. Among 3 surfactants, the solubility of exemestane in Labrasol $(40.66 \pm 0.80 \mathrm{mg} / \mathrm{ml})$ was higher than CremophorRH40 $(14.70 \pm 0.27 \mathrm{mg} / \mathrm{ml})$ and Cremophor EL $(33.06 \pm 0.44 \mathrm{mg} / \mathrm{ml})$. However, emulsifying capacity for the selected lipid blend (Labrafac CC and Compritol 888ATO) of Labrasol was the lowest among three screened surfactants. The emulsion obtained from the mixture of the lipid blend and Labrasol was found to be white, instable and rapidly delaminated at room temperature while the other emulsions produced by using other surfactants (Cremophor RH40 or Cremophor EL) were clear, transparent and stable. Moreover, it was observed that the mixture of Cremophor RH40 and Lutrol E-400 provided a clearer and more stable emulsion than the mixture of Cremophor EL and Lutrol E-400 at the same ratio. Therefore, Cremophor RH40 was selected as a surfactant for NLC formulation.

\section{Optimization data analysis and validation of optimization model}

After the initial screening of excipients, Labrafac CC, Compritol 888ATO, Cremophor RH40 and Lutrol E-400 were chosen as liquid lipid, solid lipid, surfactant, co-surfactant of EXE-NLC formulations. The values of independent variables and their responses of 10 formulations generated by Design Expert software are shown in table 2. The ranges of particle size $\left(\mathrm{Y}_{1}\right)$, polydispersity index $\left(\mathrm{Y}_{2}\right)$, entrapment efficiency $\left(\mathrm{Y}_{3}\right)$ and drug loading $\left(\mathrm{Y}_{4}\right)$ were found to be 36$234 \mathrm{~nm}, 0.112-0.383,91.24-96.60 \%$ and $0.96-1.94 \%$, respectively.

Table 2: The independent variables of 10 formulations (F1-F10) and their responses

\begin{tabular}{|c|c|c|c|c|c|c|c|}
\hline \multirow[t]{2}{*}{ Formulation } & \multicolumn{3}{|c|}{ Independent variables } & \multicolumn{4}{|c|}{ Dependent variables } \\
\hline & $X_{1}(\%)$ & $X_{2}(\%)$ & $X_{3}(\%)$ & $Y_{1}(\mathrm{~nm})$ & $\mathbf{Y}_{2}$ & $Y_{3}(\%)$ & $Y_{4}(\%)$ \\
\hline F1 & 30 & 2 & 6 & $127.85 \pm 5.59$ & $0.142 \pm 0.007$ & $95.68 \pm 0.36$ & $1.24 \pm 0.006$ \\
\hline F2 & 10 & 4 & 8 & $102.70 \pm 2.97$ & $0.220 \pm 0.009$ & $95.36 \pm 0.10$ & $0.96 \pm 0.006$ \\
\hline F3 & 30 & 4 & 8 & $112.45 \pm 0.64$ & $0.200 \pm 0.018$ & $96.60 \pm 0.03$ & $0.97 \pm 0.002$ \\
\hline F4 & 30 & 2 & 4 & $101.16 \pm 2.60$ & $0.161 \pm 0.002$ & $95.30 \pm 0.98$ & $1.94 \pm 0.093$ \\
\hline F5 & 10 & 4 & 6 & $52.40 \pm 3.73$ & $0.160 \pm 0.019$ & $95.10 \pm 0.52$ & $1.27 \pm 0.009$ \\
\hline F6 & 30 & 2 & 8 & $180.85 \pm 1.06$ & $0.184 \pm 0.028$ & $96.29 \pm 0.07$ & $0.96 \pm 0.020$ \\
\hline F7 & 10 & 4 & 4 & $36.26 \pm 0.01$ & $0.128 \pm 0.006$ & $95.77 \pm 0.81$ & $1.89 \pm 0.065$ \\
\hline F8 & 10 & 2 & 4 & $112.95 \pm 3.75$ & $0.215 \pm 0.015$ & $91.24 \pm 0.03$ & $1.75 \pm 0.022$ \\
\hline F9 & 30 & 4 & 4 & $45.10 \pm 0.46$ & $0.112 \pm 0.006$ & $96.26 \pm 0.10$ & $1.88 \pm 0.017$ \\
\hline F10 & 10 & 2 & 6 & $234.25 \pm 4.45$ & $0.383 \pm 0.006$ & $92.85 \pm 0.38$ & $1.19 \pm 0.050$ \\
\hline
\end{tabular}

Values are expressed as mean \pm SD; $n=3$, The data in table 2 were used as inputs for BCPharSoft OPT to study on the cause-effect relations and optimize the EXE-NLC formulation., Training parameters were set at: -Test groups: $Y_{1}(6,9), Y_{2}(2,7), Y_{3}(6,8)$ and $Y_{4}(2,7)$, - Transfer function: Back Propagation Learning

Table 3: Model statistics from BCPharSoft OPT outputs

\begin{tabular}{lll}
\hline Dependent variables & $\mathbf{R}^{2}$ training & $\mathbf{R}^{2}$ test \\
\hline$Y_{1}$ & 0.99 & 1.00 \\
$Y_{2}$ & 0.95 & 0.98 \\
$Y_{3}$ & 0.92 & 0.97 \\
$Y_{4}$ & 1.00 & 1.00 \\
\hline
\end{tabular}

All $\mathrm{R}^{2}$ values which were found to be more than 0.9 indicated a very good reliability of the models (table 3). Therefore, these models could be used for multivariate optimization.

The three-dimensional (3D) response surface plots were used to study the interaction effects of two independent variables on the dependent variables at one time when the third variable was kept at a constant level.

\section{Effects of variables on particle size}

The average particle size of all formulations (F1-F10) was found to be between $36.26 \mathrm{~nm}$ and $234.25 \mathrm{~nm}$ (table 2). Particle size analysis demonstrated the positive relationships with liquid lipid to total lipid ratio $\left(\mathrm{X}_{1}\right)$, total lipid concentration $\left(\mathrm{X}_{3}\right)$ and negative relationship with surfactant concentration $\left(\mathrm{X}_{2}\right)$.

Surfactant concentration plays an important role in determining the particle size of EXE-NLCs. It is evident from fig. 4A that particle size $\left(\mathrm{Y}_{1}\right)$ decreases with increasing surfactant concentration $\left(\mathrm{X}_{2}\right)$. This relation was in accordance with the rule reported previously by Araujo J [19], Chaudhary S [20], Ferreira M [21], Gonzalez-Mira E [22], Jain K [23], Pokharkar VB [24], Pradhan M [18], Phatak AA [25], Shah M [26], Yang CR [27]. Increase in surfactant concentration results in the reduction of interfacial tension between the lipid and aqueous phase, thus, produces the smaller particles. Additionally, the surfactant molecules could stabilize and prevent the coalescence of microemulsion droplets.
As presented in fig. $4 \mathrm{~B}$, the particle size $\left(\mathrm{Y}_{1}\right)$ increases with raising the total lipid concentration $\left(\mathrm{X}_{3}\right)$. Similar results were previously reported by Araujo J [17], Jain K [23], Aslam M [28], Kumbhar DD [29], Mandpe L [30].

This can be explained by the tendency of increasing collisions and aggregation of microemulsion droplets at high concentration. When the total lipid concentration increases, the viscosity increases and leads to higher surface tension and thus larger particle size.

\section{Effects of variables on polydispersity index}

Polydispersity index is an indicator of the homogeneity of particle size distribution. The higher the polydispersity index, the lower the uniformity of nanoparticles. The polydispersity index $\left(\mathrm{Y}_{2}\right)$ of 10 formulations varied from $0.112 \pm 0.006$ to $0.383 \pm$ 0.006 .

It is observed that PDI values $\left(\mathrm{Y}_{2}\right)$ decrease with decreasing total lipid concentration $\left(\mathrm{X}_{3}\right)$ from high to middle values (fig. 5). Similar results were also reported by Araujo J [17]. Nanoparticles tend to accumulate and increase aggregation at high total lipid concentration due to the van der Waal forces of attraction and may lead to an increase in PDI values. 

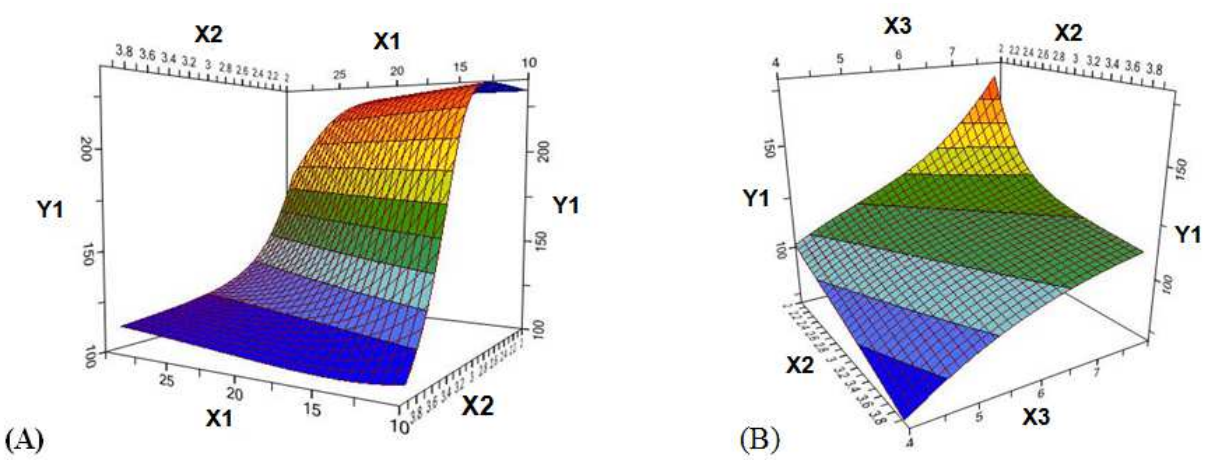

Fig. 4: Response surface plot showing the effect of $(A)$ liquid lipid to total lipid ratio $\left(X_{1}\right)$ and surfactant concentration $\left(X_{2}\right)$ on particle size $\left(\mathrm{Y}_{1}\right)$; (B) surfactant concentration $\left(\mathrm{X}_{2}\right)$ and total lipid concentration $\left(\mathrm{X}_{3}\right)$ on particle size $\left(\mathrm{Y}_{1}\right)$

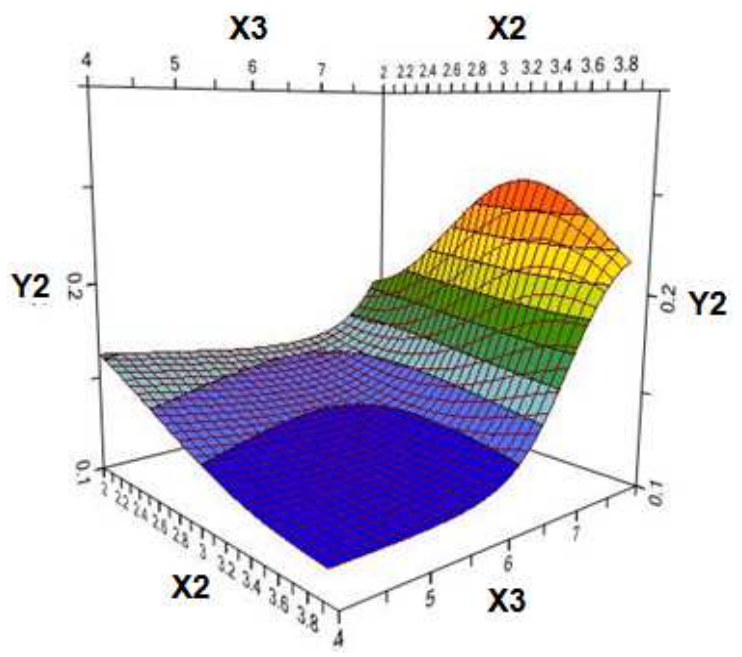

Fig. 5: Response surface plot showing the effect of surfactant concentration $\left(\mathrm{X}_{2}\right)$ and total lipid concentration $\left(\mathrm{X}_{3}\right)$ on polydispersity index $\left(\mathrm{Y}_{2}\right)$

\section{Effects of variables on entrapment efficiency}

The entrapment efficiency of 10 formulations was found to be between $91.24 \pm 0.03 \%$ and $96.60 \pm 0.03 \%$ as shown in table 2 . Entrapment efficiency demonstrates a significant positive relationship with liquid lipid to total lipid ratio $\left(\mathrm{X}_{1}\right)$, surfactant concentration $\left(\mathrm{X}_{2}\right)$ and total lipid concentration $\left(\mathrm{X}_{3}\right)$ (fig. 6).

The entrapment is mainly due to the solubility of exemestane in the solid and liquid lipids and the partition of exemestane between the

(A)

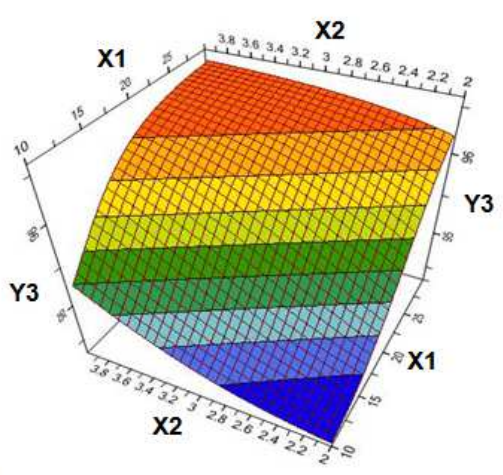

oil phase and the aqueous phase. Exemestane is a lipophilic compound, therefore, higher exemestane loading could be achieved at a high liquid lipid to total lipid ratio $\left(\mathrm{X}_{1}\right)$ and total lipid concentration $\left(\mathrm{X}_{3}\right)$ which decreases the exemestane partition in the outer space and leads to higher entrapment efficiency. The incorporation of liquid lipid into solid lipid could lead to a reduction of crystallinity and increase the imperfections in the crystal lattice which helps to accommodate the higher amount of exemestane and results in increasing entrapment efficiency. This rule was found to be in accordance with the rule reported previously by Gonzalez-Mira E [22], Jain K [23], Pradhan M [18], Aslam M [28], Zhang W [17], Zhang X [31].

It is observed from fig. 6B that entrapment efficiency $\left(\mathrm{Y}_{3}\right)$ increases when surfactant concentration $\left(\mathrm{X}_{2}\right)$ increases. Similar results were also reported by Chaudhary S [20], Gonzalez-Mira E [22], Jain K [23], Pradhan M [18], Phatak AA [25], Shah M [26], Yang CR [27], Aslam M [28], Mandpe L [30]. The positive relationship of entrapment efficiency with the surfactant concentration can be attributed to the ability of the surfactant system to increase the viscosity of aqueous phase with increasing concentration thereby decreasing the diffusion speed of exemestane and increasing the entrapment efficiency. The positive effect of surfactant concentration on entrapment efficiency could also be explained by the increased surface area when smaller particles are formed, where exemestane molecules were adhered or attached. This also could be due to the availability of adequate surfactant which facilitated exemestane to remain within the lipid particles and/or on the surface of the particles results in high entrapment efficiency.

\section{Effects of variables on drug loading}

The drug loading of different formulations was found to be between $0.96 \pm 0.020 \%$ and $1.94 \pm 0.093 \%$ as shown in table 2. Fig. 7 shows that drug loading $\left(\mathrm{Y}_{4}\right)$ increases when liquid lipid to total lipid ratio $\left(\mathrm{X}_{1}\right)$ increases.
(B)

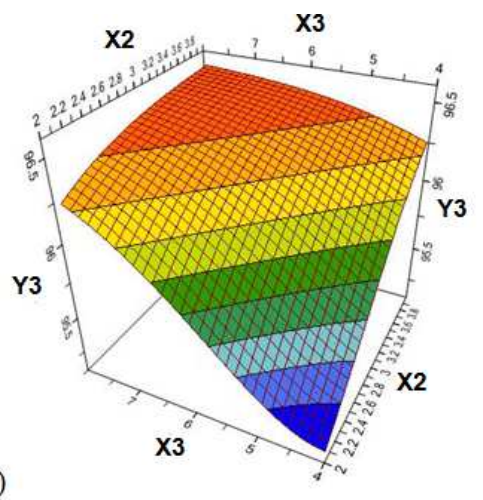

Fig. 6: Response surface plot showing the effect of $(A)$ ratio of liquid lipid to total lipid $\left(X_{1}\right)$ and surfactant concentration $\left(X_{2}\right)$ on entrapment efficiency $\left(Y_{3}\right)$; $(B)$ surfactant concentration $\left(X_{2}\right)$ and total lipid concentration $\left(X_{3}\right)$ on entrapment efficiency $\left(Y_{3}\right)$ 


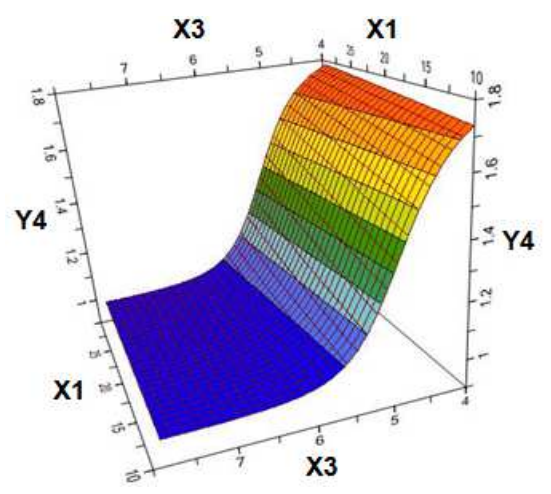

Fig. 7: Response surface plot showing the effect of liquid lipid to total lipid ratio $\left(X_{1}\right)$ and total lipid concentration $\left(X_{3}\right)$ on drug loading $\left(\mathrm{Y}_{4}\right)$

Liquid lipid acts as a solubilizing agent for exemestane at room temperature and provides the additional spaces for exemestane to accommodate and prevents exemestane from diffusing to the external phase, results in increasing drug loading. This relation was found to be in accordance with the rule reported previously by Jain K [23], Yang CR [27], Zhang X [31].

\section{Optimisation of EXE-NLC formulation}

The optimized EXE-NLC formulation was achieved with $24 \%(\mathrm{w} / \mathrm{w})$ liquid lipid to total lipid ratio, $4 \%(\mathrm{w} / \mathrm{v})$ surfactant concentration and $4 \%(\mathrm{w} / \mathrm{v})$ total lipid concentration. Three replicated batches of the optimised EXE-NLC formulation were prepared to confirm the validity of the optimization procedure. The EXE-NLCs showed a narrow size distribution (fig. 8). Particle size, polydispersity index, entrapment efficiency and drug loading of the optimized EXE-NLC formulation were found to be at $41.787 \pm 1.282 \mathrm{~nm}, 0.110 \pm 0.008$, $97.605 \pm 0.503 \%$ and $1.935 \pm 0.018 \%$, respectively.

Table 4 demonstrates that the observed values were in good agreement with the predicted values $(p>0.05)$. Therefore, the optimized EXE-NLC formulation was confirmed with $40 \mathrm{mg}$ exemestane, $0.48 \mathrm{~g}$ Labrafac CC, $1.52 \mathrm{~g}$ Compritol 888AT0, $2.00 \mathrm{~g}$ Cremophor RH40, 0.2 g Lutrol E-400 and distilled water qs to 50 $\mathrm{ml}$.

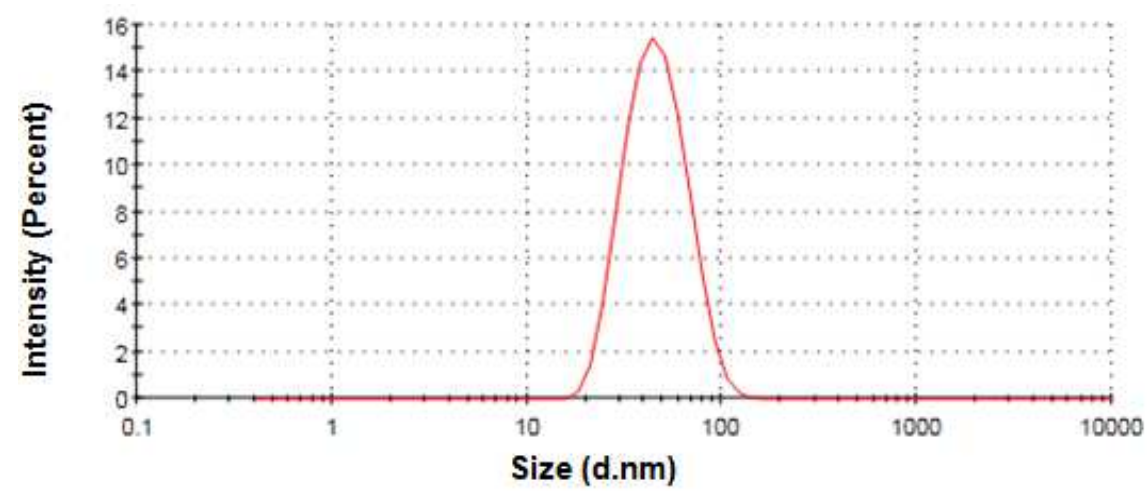

Fig. 8: Size distribution of optimized EXE-NLC formulation. The values are expressed as mean $\pm S D ; n=3$

Table 4: Comparison of the predicted and observed responses of the optimized EXE-NLC formulation

\begin{tabular}{lllll}
\hline Responses & $\mathbf{Y}_{\mathbf{1}}(\mathbf{n m})$ & $\mathbf{Y}_{\mathbf{2}}$ & $\mathbf{Y}_{\mathbf{3}} \mathbf{( \% )}$ & $\mathbf{Y}_{\mathbf{4}} \mathbf{( \% )}$ \\
\hline Predicted & 42.823 & 0.121 & 96.396 & 1.906 \\
Observed & $41.787 \pm 1.282$ & $0.110 \pm 0.008$ & $97.605 \pm 0.503$ & $1.935 \pm 0.018$ \\
P-value & 0.371 & 0.195 & 0.077 & 0.148 \\
\hline
\end{tabular}

Values are expressed as mean $\pm \mathrm{SD} ; \mathrm{n}=3$

\section{CONCLUSION}

NLC preparation of exemestane is possible using a hot sonication technique. Effects of liquid lipid to total lipid ratio, surfactant concentration, and total lipid concentration on the particle size, polydispersity index, entrapment efficiency and drug loading of EXENLCs were investigated. The optimized EXE-NLC formulation suggested by the BCPharSoft OPT intelligent software contained 40 mg exemestane, $0.48 \mathrm{~g}$ Labrafac CC, $1.52 \mathrm{~g}$ Compritol 888ATO, $2.00 \mathrm{~g}$ Cremophor RH40, $0.2 \mathrm{~g}$ Lutrol E-400 and distilled water qs to $50 \mathrm{ml}$. Three replicates of the optimized formulation were prepared and the observed responses were in good agreement with the predicted values which confirmed the optimized EXE-NLC formulation.

\section{AUTHOR CONTRIBUTION}

There are three authors who contribute to this manuscript. The percentages of the contribution of Le Quoc Thang, Nguyen Duc Hanh and Do Quang Duong are 40\%, 45\% and 15\%, respectively.

\section{CONFLICT OF INTERESTS}

All authors declare that this article content has no conflict of interest

\section{REFERENCES}

1. Deeks ED, Scott LJ. Exemestane: a review of its use in postmenopausal women with breast cancer. Drugs 2009;69:889-918.

2. Suzuki T, Miki Y, Nakamura Y, Moriya T, Ito K, Ohuchi N, et al. Sex steroid-producing enzymes in human breast cancer. Endocr Relat Cancer 2005;12:701-20.

3. Singh AK, Chaurasiya A, Singh M, Upadhyay SC, Mukherjee R, Khar RK. Exemestane loaded self-micro emulsifying drug delivery system (SMEDDS): development and optimization. AAPS PharmSciTech 2008;9:628-34.

4. Hiremath PS, Soppimath KS, Betageri GV. Proliposomes of exemestane for improved oral delivery: formulation and in vitro evaluation using PAMPA, Caco-2 and rat intestine. Int J Pharm 2009;380:96-104.

5. Kumar A, Sawant K. Encapsulation of exemestane in polycaprolactone nanoparticles: optimization, characterization, and release kinetics. Cancer Nanotechnol 2013;4:57-71.

6. Li Z, Liu K, Sun P, Mei L, Hao T, Tian Y, et al. Poly(D, L-lactideco-glycolide)/montmorillonite nanoparticles for improved oral delivery of exemestane. J Microencapsul 2013;30:432-40. 
7. Srinivas P, Sumapriya T. Exemestane loaded polymeric nanoparticles for oral delivery. Int J Nano Dimens 2014;5:539-48.

8. Rane SS, Anderson BD. What determines drug solubility in lipid vehicles: is it predictable? Adv Drug Delivery Rev 2008;60:638-56.

9. Porter CJ, Pouton CW, Cuine JF, Charman WN. Enhancing intestinal drug solubilization using lipid-based delivery systems. Adv Drug Delivery Rev 2008;60:673-91.

10. Doktorovova S, Souto EB. Nanostructured lipid carrier-based hydrogel formulations for drug delivery: a comprehensive review. Expert Opin Drug Delivery 2009;6:165-76.

11. Ghadi R, Dand N. BCS class IV drugs: highly notorious candidates for formulation development. J Controlled Release 2017;248:71-95.

12. Jenning V, Thünemann AF, Gohla SH. Characterisation of a novel solid lipid nanoparticle carrier system based on binary mixtures of liquid and solid lipids. Int J Pharm 2000;199:167-77.

13. Souto EB, Wissing SA, Barbosa CM, Müller RH. Development of a controlled release formulation based on SLN and NLC for topical clotrimazole delivery. Int J Pharm 2004;278:71-7.

14. Kavitha K, Kanagathara N. Optimization and solubilization study of novel nanoemulsion formulation for 5-fluorouracil by applying pseudoternary phase diagram. Asian J Pharm Clin Res 2014;7:137-9.

15. Tzachev CT, Svilenov HL. Lipid nanoparticles at the current stage and prospects: a review article. Int J Pharm Sci Rev Res 2013;18:103-15.

16. Shaji J, Shaikh M. Formulation, optimization, and characterization of biocompatible inhalable D-cycloserineloaded alginate-chitosan nanoparticles for pulmonary drug delivery. Asian J Pharm Clin Res 2016;9:82-95.

17. Zhang $\mathrm{W}$, Li X, Ye $\mathrm{T}$, Chen $\mathrm{F}$, Sun $\mathrm{X}$, Kong J, et al. Design, characterization, and in vitro cellular inhibition and uptake of optimized genistein-loaded NLC for the prevention of posterior capsular opacification using response surface methodology. Int J Pharm 2013;454:354-66.

18. Pradhan M, Singh D, Murthy SN, Singh MR. Design, characterization and skin permeating potential of Fluocinolone acetonide loaded nanostructured lipid carriers for topical treatment of psoriasis. Steroids 2015;101:56-63.

19. Araujo J, Gonzalez-Mira E, Egea MA, Garcia ML, Souto EB. Optimization and physicochemical characterization of triamcinolone acetonide-loaded NLC for ocular antiangiogenic applications. Int J Pharm 2010;393:168-76.

20. Chaudhary S, Garg T, Murthy RS, Rath G, Goyal AK Development, optimization and evaluation of long chain nanolipid carrier for hepatic delivery of silymarin through lymphatic transport pathway. Int J Pharm 2015;485:108-21.

21. Ferreira M, Chaves LL, Lima SA, Reis S. Optimization of nanostructured lipid carriers loaded with methotrexate: a tool for inflammatory and cancer therapy. Int J Pharm 2015;492:65-72.

22. Gonzalez-Mira E, Egea MA, Souto EB, Calpena AC, García ML Optimizing flurbiprofen-loaded NLC by central composite factorial design for ocular delivery. Nanotechnology 2010;22:045101.

23. Jain K, Sood S, Gowthamarajan K. Optimization of artemetherloaded NLC for intranasal delivery using central composite design. Drug Delivery 2015;22:940-54.

24. Pokharkar VB, Shekhawat PB, Dhapte VV, Mandpe LP. Development and optimization of eugenol loaded nanostructured lipid carriers for periodontal delivery. Int J Pharm Pharm Sci 2011;3:138-43.

25. Phatak AA, Chaudhari PD. Development and evaluation of nanostructured lipid carrier (NLC) based topical delivery of an anti-inflammatory drug. J Pharm Res 2013;7:677-85.

26. Shah M, Agrawal Y. Development of ciprofloxacin HCl-based solid lipid nanoparticles using ouzo effect: an experimental optimization and comparative study. J Dispersion Sci Technol 2013;34:37-46

27. Yang CR, Zhao XL, Hu HY, Li KX, Sun X, Li L, et al. Preparation, optimization and characteristic of huperzine loaded nanostructured lipid carriers. Chem Pharm Bull 2010;58:656-61.

28. Aslam M, Aqil M, Ahad A, Najmi AK, Sultana Y, Ali A. Application of box-behnken design for the preparation of glibenclamide loaded lipid-based nanoparticles: optimization, in vitro skin permeation, drug release and in vivo pharmacokinetic study. J Mol Liq 2016;219:897-908.

29. Kumbhar DD, Pokharkar VB. Engineering of a nanostructured lipid carrier for the poorly water-soluble drug, bicalutamide: physicochemical investigations. Colloids Surf A 2013;416:32-42.

30. Mandpe L, Pokharkar V. Quality by design approach to understand the process of optimization of iloperidone nanostructured lipid carriers for oral bioavailability enhancement. Pharm Dev Technol 2015;20:320-9.

31. Zhang X, Liu J, Qiao H, Liu H, Ni J, Zhang W, et al. Formulation optimization of dihydroartemisinin nanostructured lipid carrier using response surface methodology. Powder Technol 2010;197:120-8.

\section{How to cite this article}

- Le Quoc Thang, Nguyen Duc Hanh, Do Quang Duong. Study on cause-effect relations and optimization of exemestane-loaded nanostructured lipid carriers. Int J Pharm Pharm Sci 2017;9(5):68-74. 